\title{
LA CORRUPCIÓN EN EL FRANQUISMO: EL FENÓMENO DEL “GRAN ESTRAPERLO”
}

\author{
Corruption in Francoism: the great 'estraperlo'
}

\author{
Miguel Ángel del Arco Blanco \\ Universidad de Granada \\ maarco@ugr.es
}

Cómo citar este artículo/Citation:

Miguel Ángel del ARCO BLANCO (2018), "La corrupción en el franquismo. El fenómeno del "Gran Estraperlo", Hispania Nova, 16, págs. 620-645. DOI: https://doi.org/10.20318/hn.2018.4050
Copyright: (c) HISPANIA NOVA es una revista debidamente registrada, con ISSN 1138-7319 y Depósito Legal M 9472-1998. Los textos publicados en esta revista están -si no se indica lo contrario- bajo una licencia Reconocimiento-Sin obras derivadas 3.0 España de Creative Commons. Puede copiarlos, distribuirlos y comunicarlos públicamente siempre que cite su autor y la revista y la institución que los publica y no haga con ellos obras derivadas. La licencia completa se puede consultar en: http://creativecommons.org/licenses/by-nd/3.0/es/deed.es

\section{Resumen:}

El artículo se centra en el estudio de la corrupción durante el régimen franquista. Discute el mito, en gran parte vigente en parte de la sociedad actual, de la inexistencia de la corrupción durante el franquismo. Para ello estudiamos un fenómeno hasta ahora no demasiado explorado: el del "gran estraperlo". Un negocio de alto rendimiento que tuvo lugar durante la posguerra, a expensas del sufrimiento, el hambre y la escasez de buena parte de la población. Fue desarrollado siempre en connivencia o con la participación directa de personas pertenecientes a la Administración franquista o cercanas a la misma. La reacción de la dictadura fue la de desarrollar importantes campañas de propaganda - castigar a los pequeños estraperlistas, mientras que toleraba el comercio clandestino y la impunidad de los principales responsables del gran estraperlo. De esta forma, la corrupción fue algo estructural dentro de la dictadura, justificándose no sólo por los intereses individuales que satisfizo, sino también porque fue un elemento esencial dentro de los mecanismos que consolidaron y dieron estabilidad al "Nuevo Estado" surgido de la guerra civil.

Palabras clave: franquismo, corrupción, estraperlo, mercado negro, poder local, personal político.
Abstract: The article studies the corruption during the Francoist regime. The myth of the absence of corruption under Francoist dictatorship is discussed. The text analyses a case of a non-very much studied phenomena: the "great estraperlo" (great black market). A highly profitable business that took place during the post-war years at the expense of the suffering, the hunger and the scarcity of a large part of the population. It was always developed with the complicity or the direct participation of members of the Francoist administration or people close to the regime. The dictatorship's reaction consisted in the display of important propaganda campaigns or in the punishment of the small black marketers, whereas it tolerated the clandestine trade and the impunity of the main culprits of the great black market. This way, corruption was structural within the dictatorship. It should be explained not only for the individual interests that it satisfied, but also because it was an essential element for the consolidation and stabilisation of the "New State" emerged during the Spanish Civil War.

Keywords: Francoism, corruption, estraperlo, black market, local authorities, political personnel, grassroots 
"Con Franco no era como ahora. Uno ganaba lo que trabajaba.

No te quitaban nada, como ahora

Y con Franco, ¿había corrupción como hay ahora?

¿Con Franco? Con Franco no había corrupción". 1

Este testimonio de un ciudadano común del mundo rural ejemplifica a la perfección un legado del franquismo respecto al periodo democrático: en primer lugar, que el pago de impuestos para mantener un sistema de bienestar es contemplado como una exacción injusta; y en segundo, lo más importante y en parte derivado de lo primero, que bajo la dictadura franquista la corrupción no existió. Esta visión concuerda con la imagen que, durante años, el dictador construyó de sí mismo. Una imagen que fue mutando desde la guerra civil, la posguerra, los años cincuenta y el periodo del "desarrollo" económico: un Franco poso de innumerables virtudes bélicas cuando eran necesarias, políticas cuando se le requirieron, nacionalistas siempre, trabajador incansable y, sobre todo al final, paternalista con un sociedad española en teoría menor de edad para alcanzar la madurez democrática. Esta imagen cincelada por el "Caudillo", por la propaganda, por sus colaboradores y partidarios, ha sido seriamente cuestionada por algunos historiadores. ${ }^{2}$ No obstante, pese a los avances historiográficos, todavía perdura la visión del régimen de Franco como algo alejado de la corrupción. ${ }^{3}$ Esta asunción no es relevante sólo porque incurra en un error histórico

\footnotetext{
Nota del autor: Este trabajo ha sido realizado en el marco del proyecto de investigación MEMOHAMBRE, "Historia y memoria del hambre: sociedad, vida cotidiana, actitudes sociales y políticas de la dictadura franquista (1939-1959)", financiado por el Ministerio de Economía y Competitividad.

${ }^{1}$ Entrevista a Juan Rodríguez Ortega. Nacido hacia 1940. Granada, 7-6-2016.

2 Paul PRESTON, El gran manipulador. La mentira cotidiana de Franco. Barcelona, Ediciones B, 2008, pp. 11-20; Ángel VIÑAS, La otra cara del Caudillo: mitos y realidades de la biografía de Franco. Barcelona, Crítica, 2015, especialmente pp. 281-377; Antonio CAZORLA, Franco: biografía de un mito. Madrid, Alianza, 2014.

${ }^{3}$ Compendio de todos estos mitos sobre la supuesta honradez del franquismo y sus hombres frente a las prácticas corruptas generalizadas del gobierno socialista de la Transición, son las páginas que Ricardo DE LA CIERVA dedica a este tema. Ver: Historias de la corrupción. Barcelona, Planeta, 1992,
} 
sino, especialmente, porque contrapone la honestidad de la dictadura, de sus políticos y partidarios a la de la democracia actual.

El concepto de "corrupción" es complejo y ha mutado a lo largo de la historia. Todavía hoy los académicos se encuentran divididos respecto a cuestiones fundamentales relativas a su definición, análisis y formas de hacerle frente. No obstante, entre el mundo antiguo, medieval, moderno y contemporáneo la corrupción siempre ha contado con dos factores esenciales que explican sus motivaciones y su práctica: el enriquecimiento personal y la utilización de los mecanismos del poder para ello. ${ }^{4}$ De hecho, pese a la tremenda diversidad que caracteriza a la corrupción, la ONG "Transparency International”, centrada en visibilizar y promover la lucha contra ella, la define hoy como "el abuso del poder utilizado para lograr el beneficio privado". ${ }^{5}$

Bajo estos términos, en el presente artículo pretendemos reflexionar sobre la corrupción en el régimen franquista. Nuestro objetivo es subrayar que ésta, como en todos los regímenes dictatoriales carentes de libertades y derechos democráticos, no fue una excepción sino más bien una norma. La corrupción puede encontrarse en todas las décadas que duró el franquismo: fue mutando, ostentando unas características, unas prácticas y unos beneficiados determinados. La corrupción fue algo estructural dentro de la dictadura, justificándose no sólo por los intereses individuales que satisfizo, sino también porque fue un elemento esencial dentro de los mecanismos que consolidaron y dieron estabilidad al "Nuevo Estado" surgido de la guerra civil.

Estos perfiles de la corrupción franquista han sido delimitados, para diversas décadas y fenómenos, por algunos trabajos hasta ahora publicados. Ángel Viñas ha revelado con una notable carga documental la corrupción de algunos destacados generales del franquismo (y de Nicolás Franco, hermano del dictador) en el contexto

pp. 268-306. De la Cierva sentencia como colofón a su trabajo, en un tono claramente ambiguo y exculpatorio, que el régimen de Franco "fue una época mixta de honradez y de corrupción, con más honradez que corrupción por lo general" (p. 306).

${ }^{4}$ Bruce BUCHAN y Lisa HILL, An Intellectual History of Political Corruption. Basingstoke, Palgrave, 2014, pp. 2-8. De la misma idea: Jens Ivo ENGELS y Frédéric MONIER, "Introduction”, en Olivier DARD, Jens Ivo ENGELS, Andreas FAHRMEIR y Frédéric MONIER (Eds.), Scandales et corruption à l'époque contemporaine, París, Armand Colin, 2014, p. 14.

${ }^{5}$ Transparency International: Recuperado de https://www.transparency.org/what-is-corruption\#define (Consulta del 10-6-2017). 
de la II Guerra Mundial: a través del empresario Juan March, el gobierno británico les hizo llegar suculentas sumas económicas para evitar la entrada de España en la contienda. ${ }^{6}$

Otros trabajos han dejado claro que la corrupción y el enriquecimiento también alcanzaron, y con bastante intensidad además, a la familia Franco y a su círculo personal más íntimo: " "donaciones" del "pueblo" (Pazo de Meirás) o de empresarios "desinteresados" (finca del Canto del Pico); empleo del Patrimonio Nacional para uso (y beneficio) particular; cacerías como medio de consecución de favores; suculentos permisos de importación concedidos al yerno del "Caudillo" (la relación entre la profesión de cirujano de éste no parece guardar demasiada relación con la comercialización de las "Vespas" en España); o incluso el escándalo de la desaparición de cuatro millones de litros de aceite de la empresa REACE en el que se vio envuelto (y del que salió impune) su hermano Nicolás Franco en los estertores de la dictadura. Gobernar el país siendo dueños de las propias reglas hizo que los Franco acumulasen, al morir el dictador, una fortuna impresionante. Entonces, sus propiedades inmobiliarias se han valorado en más de 1.000 millones de pesetas, y la fortuna global (empresas, cuentas corrientes -la mayoría de ellas fuera de España-) en más de 100.000 millones de pesetas. $^{8}$

La época posterior a 1951 también ha recibido la atención de algunos investigadores. Se trató de una corrupción menos generalizada que la de posguerra y más especializada en negocios como las importaciones, el sector inmobiliario o la

\footnotetext{
${ }^{6}$ Ángel VIÑAS, Sobornos. De cómo Churchill y March compraron a los generales de Franco. Barcelona, Crítica, 2016, p. 488.

${ }^{7}$ Hace tiempo se sugirió que también los colaboradores más íntimos de Franco se enriquecieron con el ejercicio del poder y, tras abandonarlo, ocuparon cómodos puestos en Consejos de Administración de empresas relevantes. Son especialmente claros los ejemplos de Lorenzo Martínez Fuset y Blas Pérez González. Ramón GARRIGA, Los validos de Franco. Barcelona, Planeta, 1981. Ver, respectivamente, pp. 120-121, 208. Sin embargo, Garriga no habla explícitamente de corrupción.

${ }^{8}$ Mariano SÁNCHEZ SOLER, Los Franco, S. A. Madrid, Oberon, 2003, pp. 100-102. El ambiente del Palacio del Pardo y de la familia de Franco: Ramón GARRIGA, La señora del Pardo. España a sus pies. Barcelona, Planeta, 1979. Sobre los negocios y ardides del hermano del "Generalísimo": Ramón GARRIGA, Nicolás Franco, el hermano brujo. Barcelona, Planeta, 1980.
} 
gestión de ayudas públicas. ${ }^{9}$ También hubo enriquecimiento de personas vinculadas al poder, así como impunidad. Ejemplo de ello pudo ser el caso de la adquisición de Juan March de la "Barcelona Traction", en el que el grupo del empresario balear adquirió un notable holding de empresas a precio muy inferior del real, recurriendo a una buena gama de ilegalidades y favoritismos con el apoyo del Gobierno. ${ }^{10}$ Posteriormente habría muchos casos más de corrupción de tipologías bastante similares a los escándalos que afectarían al periodo democrático: la Agenda Rivara, relacionada con evasión de capitales; la sospechosa quiebra de Manufacturas Madrileñas, de la que nunca se depuraron responsabilidades, quizá por el papel central jugado por Nicolás Franco; o el caso SOFICO, por el que una sociedad inmobiliaria afincada en la Costa del Sol en la que tenían intereses personas cercanas al régimen simuló una quiebra fraudulenta. ${ }^{11}$ Pero quizá el caso de corrupción más célebre de los años del "milagro español" fue el "escándalo MATESA". En ello tuvo mucho que ver la lucha entre falangistas y tecnócratas por el poder, como incluso la prensa de entonces reflejó. Se descubrió que la empresa "Maquinaria Textil del Norte de España S. A." (MATESA) había recibido una financiación privilegiada del ente público "Banco de Crédito Industrial" para potenciar las exportaciones de un modelo de telar sin lanzadera. Sin embargo, salió a la luz que por lo menos un tercio de las ventas eran ficticias y, pese a eso, la financiación pública prosiguió. Que el director de MATESA y los cargos ministeriales responsables del trato privilegiado perteneciesen al Opus Dei hizo que algunos insinuasen incluso una financiación encubierta de la institución. Lo sucedido contribuyó al cambio de gobierno en 1969, aunque paradójicamente el Opus Dei saldría reforzado. Pese al revuelo en los medios de comunicación, el proceso judicial y

\footnotetext{
${ }^{9}$ Carlos BARCIELA, "Franquismo y corrupción económica". Historia Social, 30 (1998), pp. 84-85. Una visión general: Enrique MARTíNEZ FARIÑAS, Escándalos financieros españoles (MATESA, REACE, Barcelona Traction, Cajas de Crédito Popular, etc.). Barcelona, Producciones Editoriales, 1976.

${ }^{10}$ Rafael ALCALDE, "El caso de la Barcelona Traction. Una revisión", Revista de Historia Industrial, 36 (2008), pp. 103-105. También: Mercedes CABRERA, Juan March (1880-1962). Madrid, Marcial Pons, 2011.

${ }^{11}$ Mariano SÁNCHEZ SOLER, Ricos por la guerra de España: el enriquecimiento de la oligarquía franquista desde 1936 hasta la transición. Madrid, Raíces, 2007, pp. 243-249.
} 
la investigación en Cortes, todo quedó en nada gracias al indulto que Franco les dispensó en $1971 .^{12}$

Los citados estudios sobre la corrupción bajo el franquismo, y la amplitud del tema condiciona que, para alcanzar los objetivos trazados y no quedarnos en un relato superficial, abordemos un fenómeno determinado de la corrupción bajo el franquismo. ${ }^{13}$ Nos referimos al estudio del "gran estraperlo", típico de los años de posguerra (1939-1952) y para el que, hasta ahora, no existen estudios específicos. Definiremos primero el fenómeno, diferenciándolo del "pequeño estraperlo", subrayando sus resultados. Después, analizaremos su funcionamiento a partir de diversos casos concretos, evidenciando que sus actores principales pertenecían al régimen o estaban muy cercanos a él. Reflexionaremos a continuación sobre la reacción del "Nuevo Estado" ante estos delitos, poniendo de manifiesto la nula voluntad de atajar el fenómeno, castigar a los culpables o cortar el problema de raíz. Terminaremos con unas conclusiones sobre las implicaciones del gran estraperlo y la corrupción en el régimen franquista.

El estudio de la corrupción del gran estraperlo nos permite aproximarnos al análisis de la gran y mediana corrupción bajo la dictadura, aquella que sólo fue posible gracias al recurso (o la tolerancia) del poder del Estado. Evidenciaremos que las prácticas corruptas acabarán teniendo un carácter político directo o indirecto: directo porque será llevada a cabo por algunas de las primeras figuras del régimen o las instituciones (alcaldes, Ejército, Falange, Fiscalía de Tasas, etc.) sobre las que se asentó; indirecto porque la generalización de dichas prácticas entre los apoyos sociales del régimen y la tolerancia plena hacia ellas garantizarán la continuidad de la dictadura.

Es preciso advertir sobre las dificultades para escribir sobre la corrupción bajo el franquismo y, en concreto, sobre el gran estraperlo. El carácter antidemocrático de la dictadura y sus medios hacen muy difícil contar con documentos que nos permitan

\footnotetext{
${ }^{12}$ Fernando JIMÉNEZ, "EI caso MATESA: un escándalo político en un régimen autoritario". Historia y política, 4 (2000), pp. 43-68.

${ }^{13}$ Además, otros aspectos son abordados en algunos trabajos de este dosier. Ver especialmente el artículo de Francisco Comín sobre la corrupción fiscal en España, el de María Rosa de Madariaga sobre la corrupción en el protectorado o el de Pablo Corral Broto sobre la corrupción y el medio ambiente bajo el franquismo.
} 
rastrear las irregularidades en el ejercicio del poder. Por otro lado, gran parte de los fondos documentales para estudiar el gran estraperlo (como la Fiscalía de Tasas y, sobre todo, la ingente documentación de la Comisaría General de Abastecimientos y Transportes) fueron destruidos por el régimen franquista e incluso después de la muerte del dictador. ${ }^{14}$ Pero además, las restricciones al acceso de archivos por parte de los gobiernos democráticos hace imposible consultar documentación hoy clasificada. Paradójicamente, la vigencia de la Ley de Secretos Oficiales de $1968,{ }^{15}$ condiciona severamente las posibilidades de escribir la historia de una dictadura franquista que, como señalábamos al principio, todavía parece gozar de una pátina de honradez frente al periodo democrático en el que vivimos.

\section{Corrupción en tiempos de hambre: el "gran estraperlo"}

La larga posguerra que siguió a la guerra civil (1939-1952) continúa, en la memoria de nuestros mayores, asociada a dos fenómenos: en primer el hambre, las pésimas condiciones socioeconómicas que afectaron especialmente a las clases más desfavorecidas; y en segundo lugar, el mercado negro y el fenómeno conocido como "estraperlo". ${ }^{16}$ Hambre y estraperlo, conceptos diferentes pero estrechamente relacionados con el funcionamiento y realidad de aquellos días: el férreo intervencionismo económico autárquico potenció la escasez, al distorsionar las leyes de la oferta y la demanda, dando lugar a la generación de un mercado negro donde los precios alcanzarían precios astronómicos. ${ }^{17}$ Así, el hambre y la escasez de algunos sólo podrían ser paliadas recurriendo a vías no oficiales, adquiriendo productos "de

\footnotetext{
14 Carlos BARCIELA, "Las investigaciones sobre el mercado negro de productos agrarios en la postguerra: situación actual y perspectivas", Revista de Historia Económica, Año III, 3, (1985), pp. 516517.

15 Fernando REY MARTÍNEZ, "Derecho de acceso a la información y secretos oficiales en el Ordenamiento Español", Revista Cuadernos Manuel Giménez Abad, 5 (2013), p. 201.

${ }^{16}$ Ejemplos: Carlos ELORDI (Ed.), Los años difíciles. El testimonio de los protagonistas anónimos de la guerra civil y la posguerra. Madrid, Aguilar, 2002; Manuel PATO MANZANO, Mater admirabilis. Vivencias de la Guerra Civil en Asturias. Barcelona, Viena, 2003.

${ }^{17}$ Carlos BARCIELA, "El mercado negro de productos agrarios en la posguerra, 1939-1953". FONTANA, Josep. España bajo el franquismo. Barcelona, Crítica, 1986, pp. 192-205.
} 
estraperlo" o, incluso, participando en estas prácticas fraudulentas, haciendo de ellas un medio de vida.

Ahora bien, asimilar el fenómeno del estraperlo a la corrupción quizá sea escribir con un trazo demasiado grueso. Existieron diversos tipos de estraperlo: uno de supervivencia, el "estraperlo de los pobres", en el que participaban las clases sociales más bajas y que no enriquecieron a sus protagonistas, sino más bien le permitieron salir adelante a ellos y a sus familias. ${ }^{18}$ Este recurso a las prácticas del mercado negro eran una forma de resistencia al modelo autárquico, incurriendo una y otra vez en ilegalidades cotidianas; ${ }^{19}$ pero además, este pequeño estraperlo no tenía como fin el enriquecimiento, sino la supervivencia, asegurando la ingestión de una dieta calórica suficiente para escapar al hambre y esquivar las enfermedades. Es el pequeño estraperlo que se desarrollaba en calles, plazas o estaciones de tren, cuyos protagonistas eran familias pobres o deshechas por la guerra. Pero además, la reacción del régimen hacia el mismo fue la de perseguirlo, castigando con multas, incautaciones de los artículos e incluso encarcelamiento de los responsables. ${ }^{20} \mathrm{En}$ suma, este pequeño estraperlo implicaba un cruce de la legalidad establecida, pero algo alejado del fenómeno de la corrupción porque, básicamente, ni era protagonizado por personas que estuviesen en las instituciones del Estado y se sirviesen de ellas para su propio fin y, también, porque practicarlo no conducía al enriquecimiento, sino a la supervivencia.

El "gran estraperlo" tuvo unas motivaciones, fisonomía y resultados muy distintos. No estuvo originado en la escasez o en la desesperación personal, sino más bien en el afán de lucro ante una situación de penuria. Los responsables fueron

18 Encarnación BARRANQUERO y Lucía PRIETO, Así sobrevivimos al hambre: estrategias de supervivencia de las mujeres de la posguerra española. Málaga, Diputación Provincial de Málaga, 2003; Miguel GÓMEZ OLIVER y Miguel Ángel DEL ARCO BLANCO, "El estraperlo: forma de resistencia y arma de represión en el primer franquismo", Studia Histórica. Historia Contemporánea, 23 (2005), pp. 179-199.

19 Óscar J. RODRÍGUEZ BARREIRA, Migas con miedo. Prácticas de resistencia en el primer franquismo. Almería 1939-1952. Almería, Universidad de Almería, 2008; CABANA, Ana. La derrota de lo épico. Valencia, Publicaciones de la Universidad de Valencia, 2013.

${ }^{20}$ Gloria ROMÁN RUIZ, Delinquir o morir. El pequeño estraperlo en la Granada de posguerra. Granada, Comares, 2015. Óscar J. RODRÍGUEZ BARREIRA, "Cambalaches: hambre, moralidad popular y mercados negros de guerra y postguerra", Historia Social, 77 (2013), pp. 149-174. A veces estaba estrechamente relacionado con el hurto: RODRÍGUEZ BARREIRA, Óscar J. "Lazarillos del Caudillo. EI hurto como arma de los débiles frente a la autarquía franquista". Historia Social, 72 (2012), pp. 65-87. 
personalidades cercanas al régimen franquista 0 , directamente, pertenecientes a sus instituciones. No consistía en la venta de productos puntuales en el mercado negro, sino más bien en el transporte y comercialización de grandes cantidades de artículos agrícolas o industriales que alcanzarían unos precios astronómicos en el mercado negro. ${ }^{21}$ Además, pese a los constantes alegatos del régimen para perseguirlo, en la mayoría de los casos no sería castigado. Es por ello que este gran estraperlo encaja perfectamente en el concepto de corrupción que esbozábamos al principio: se desarrolla con la aquiescencia, complicidad o incluso participación de personal del Estado, contraviene la legalidad establecida y genera el enriquecimiento de sus actores.

La diferencia entre los precios oficiales fijados por el régimen franquista y los precios del mercado negro era abismal. Pese a la dificultad de contar con fuentes fiables, algunos historiadores han realizado estudios relevantes sobre esta cuestión. Carlos Barciela, por ejemplo, ha señalado que los precios oficiales del trigo no fueron favorables a los cultivadores, pero sí lo serían los precios al venderlo en el mercado negro (hasta cinco o seis veces más que los oficiales) ${ }^{22}$; algo similar sucedería con los productos agrícolas, que multiplicarían por dos y por tres los precios de tasa oficiales. ${ }^{23}$ Más lucrativo incluso era el negocio del aceite, donde el precio de estraperlo llegó a ser cuatro veces el oficial, suponiendo un valor real del 180 por 100 respecto a los precios oficiales fijados por el régimen (entre 1940 y 1952). Las dimensiones del mercado negro de productos agrícolas también son espectaculares. Si en el trigo se estima que durante los cuarenta superó el 50 por 100 de la cosecha comercializada (llegando a superar el 60 por 100 en algunas campañas), en el aceite se afirma que nada menos que un 20 por 100 de la producción fue comercializada en el mercado ilegal. ${ }^{24}$ Aunque

\footnotetext{
${ }^{21}$ Carlos BARCIELA, "La España del estraperlo", José Luis GARCIA DELGADO (Ed.), El primer franquismo. España durante la Segunda Guerra Mundial. Madrid, Siglo XXI, 1989, especialmente pp. 116-117.

${ }^{22}$ Carlos BARCIELA y Aurelio GARCíA GONZÁLEZ, "Un análisis crítico de las series estad19ísticas de los precios del trigo entre 1937 y 1980", Agricultura y Sociedad, 29 (1983), pp. 86-87.

${ }^{23}$ Carlos BARCIELA, "Las investigaciones sobre el mercado negro de productos agrarios en la postguerra: situación actual y perspectivas", Revista de Historia Económica, Año III, 3, (1985), p. 514.

${ }^{24}$ Para el trigo: Carlos BARCIELA, "El «estraperlo» de trigo en la posguerra". Moneda y Crédito, 151 (1981), p. 27. Para el aceite: Thomas CHRISTIANSEN, "Intervención del Estado y mercado negro en el sector oleícola durante el primer Franquismo", Historia Agraria, 27 (2002), p. 235 y 222.
} 
existió un mercado negro de casi todo (caucho, hierro, lino, algodón o cualquier materia prima para la industria), las mayores elevaciones de precios las alcanzaron los productos alimenticios, los que diariamente componían la base de la dieta de las clases populares. Para el caso de Bilbao, por ejemplo, el análisis de los precios de 40 artículos en el mercado negro de aquellos años mostraba que algunos se multiplicaban en ocasiones por diez, veinte o incluso treinta respecto al oficial. ${ }^{25}$

Esta tendencia en los precios se sostendría a lo largo de toda la década de los cuarenta, con fluctuaciones en determinados productos y estaciones del año. Ello fue debido a la férrea intervención que el "Nuevo Estado" sometió a la economía y a los productos más necesarios para la alimentación o el funcionamiento de la industria: los precios poco remuneradores hicieron que buena parte de la producción pasase a ser comercializada en el mercado negro, disparando los precios y contribuyendo a generar una escasez de productos algo artificial y especialmente perjudicial para las clases más bajas. ${ }^{26}$ Algunos economistas dentro del régimen advirtieron sobre esta dinámica, ${ }^{27}$ pero aun así la intervención autárquica pervivió hasta comienzos de los cincuenta, cuando el agotamiento de la economía española, la presión estadounidense e incluso protestas como la huelga de tranvías de 1951 en Barcelona propiciaron una tímida liberalización. Como se ha afirmado, este abrazo constante de las políticas intervencionistas se justifica por los intereses de "lobbies" que se beneficiaban de la marcha de la política autárquica, de personalidades concretas que las diseñaban y manejaban y, también, por la presión del propio personal de los organismos de intervención que temían perder su puesto de trabajo. ${ }^{28}$ Hubo por tanto un apoyo, presión o conformidad desde dentro del régimen por el mantenimiento de una

\footnotetext{
${ }^{25}$ Los de precio más elevado eran el pan, el azúcar, el aceite, la lenteja, la alubia blanca y el arroz. Ver: Manuel GONZÁLEZ PORTILLA y José María GARMENDIA URDANGARÍN, "Corrupción y mercado negro: nuevas formas de acumulación capitalista", en Glicerio SÁNCHEZ RECIO y Julio TASCÓN FERNÁNDEZ (Eds), Los empresarios de Franco. Política y economía en España, 1936-1957. Barcelona, Crítica, 2003, pp. 252-253.

${ }^{26}$ Carlos BARCIELA, "La España del estraperlo", op. cit.,pp. 107-109.

${ }^{27}$ Juan ZABALZA, "La contribución de Manuel de Torres a la economía agraria en España (1930-1960)". Historia Agraria. Revista de agricultura e historia rural, 31 (2004), pp. 113-139.

${ }^{28}$ Carlos BARCIELA, "Franquismo y corrupción económica", Historia Social, 30 (1998), pp. 91-93.

Sobre el lobby de la agricultura: Carlos BARCIELA, "El lobby agrario en la España franquista", Glicerio SÁNCHEZ RECIO y Julio TASCÓN FERNÁNDEZ (Eds.), Los empresarios de Franco. Política y economía en España, 1936-1957, Barcelona, Crítica, 2003.
} 
economía intervenida en la que las reglas del mercado estaban aparentemente ausentes, y en la que con los convenientes contactos políticos determinaban el éxito empresarial o el progreso económico personal.

La perduración de la política intervencionista típica de la autarquía respondía a unos intereses económicos bien fundados. En el medio rural, algún estudio de caso ha subrayado el enriquecimiento del personal político vinculado al poder local de la dictadura: alcaldes y gestores aumentaron su patrimonio urbano y rural (o accedieron a la propiedad) durante los años cuarenta. ${ }^{29}$ Por otro lado, tras la guerra civil, se ha identificado el surgimiento de una nueva clase alta, unos "nuevos ricos", consecuencia directa del gran estraperlo y de los beneficios que la política autárquica (y su cercanía con el régimen) les procuraban. El ejemplo palpable de todo ello sería Dionisio Martín Sanz: falangista de primera hora e ingeniero agrónomo, procurador en Cortes pero, sobre todo, promotor y Secretario General del Servicio Nacional del Trigo durante la guerra y, después de ella, Subsecretario de Agricultura. La posguerra no fue un mal tiempo para él: justo al concluir la guerra compró 1.600 hectáreas en la provincia de Jaén, y ya en 1950 encabezaba una empresa agrícola que contaba con más de 6.000 hectáreas y que, utilizando sus contactos políticos, suministraba productos a otras empresas públicas. ${ }^{30}$

Las prácticas corruptas derivadas del estraperlo no concluían con la mera comercialización de productos. Asociadas a ellas tuvo lugar una verdadera "cadena de delitos" asociados al fraude fiscal. Cada artículo comercializado, pero también los beneficios generados, escaparon al control de la Hacienda. A ello habría que sumar un fraude fiscal de dimensiones colosales potenciado por un sistema repleto de regulaciones, que benefició especialmente a las clases más acomodadas y grupos sociales leales al régimen. Respecto al sector agrario se ha demostrado que, en cuanto a Contribución Rústica, éste dejó de pagar "al menos una cantidad igual a la que efectivamente aportó". Por no hablar de la Contribución General sobre la Renta en

\footnotetext{
${ }^{29}$ Miguel Ángel DEL ARCO BLANCO, 'Hambre de siglos'. Mundo rural y apoyos sociales del franquismo en Andalucía Oriental (1936-1951), Granada, Comares, 2007, pp. 184-186.

${ }^{30}$ Miguel ARTOLA, El fin de la clase ociosa. De Romanones al estraperlo, Madrid, Alianza, 2015, pp. 242-245.
} 
la que, pese a ser mínima, el fraude "más que una excepción" fue "la norma". 31 Los más beneficiados de estas prácticas fueron los grandes, medianos y pequeños propietarios, columna vertebral de las bases sociales del régimen. No es nada casual, por tanto, que durante toda la dictadura el Ejecutivo no llevase a cabo ninguna reforma ni ninguna práctica efectiva para frenar esta tendencia que, otra vez, facilitaba el enriquecimiento personal. ${ }^{32}$

\section{Corrupción estatal: funcionamiento y actores}

Descendamos al escenario del gran estraperlo para estudiar su funcionamiento, actores y resultados. Comencemos por un caso concreto que, a nuestro juicio, revela a la perfección las características del fenómeno. En febrero de 1942 se informaba sobre la salida "de estraperlo" del pueblo de Teba (Málaga) de "dos camiones de garbanzos" que marchaban hacia Algeciras (Cádiz). La noticia apuntaba a diversos actores: el vendedor era "D. Manuel Lora Vera", acaudalado arrendatario del molino de donde partió la mercancía; y el comprador era Carlos Guzmán, que residía en la ciudad de Málaga, "jugador profesional que frecuenta mucho el café Suizo de esa capital". Como puede verse, dos personas de acomodada posición como para sufragar la operación y quizá lo suficientemente bien conectadas como para hacerla posible. Pero por supuesto, ellos no intervinieron en el traslado: fueron dos vecinos del municipio de Teba (José Pinto, de apodo "Pintillo" y José García Briceño, apodado "Chascarro"), presumiblemente de posición más modesta, los que transportaron en los camiones la mercancía. No obstante, no fueron descubiertos ni detenidos: el citado informe venía firmado por el gobernador civil de Málaga (entonces Emilio Lamo de Espinosa), responsable del abastecimiento de la provincia quien, daba cuenta a los Inspectores de la Fiscalía de Tasas (organismo encargado de velar por el cumplimiento de los precios

\footnotetext{
${ }^{31}$ Carlos BARCIELA, "Fraude fiscal y mercado negro durante el primer franquismo". Hacienda Pública Española, 1 (1994), pp. 374-376 y 379.

${ }^{32}$ A pesar de las reformas tributarias de 1940, 1957 y 1964 tras la guerra civil el fraude fiscal se agudizó respecto a épocas anteriores. Ver: Francisco COMíN, "Corrupción y fraude fiscal en la España contemporánea", Manuel GONZÁLEZ JIMÉNEZ, Horst PIETSSCHMANN, Francisco COMíN, Joseph PÉREZ, Instituciones y corrupción en la Historia. Valladolid, Universidad de Valladolid, 1998, pp. 71-72 y 81-82.
} 
oficiales) que se estaban produciendo casos de gran estraperlo en la provincia. ${ }^{33}$ Pero el informe del gobernador civil no decía toda la verdad. El gran estraperlista de Teba, Manuel Lora Vera, tenía una vinculación directa con el "Nuevo Estado": su hermano había sido víctima de la violencia republicana durante la guerra y, él mismo, entre 1939 y 1954 fue alcalde y jefe local de FET y de las JONS de la localidad, además de ocupar cargos de relevancia en la Hermandad de Labradores. ${ }^{34}$

El desarrollo y la generalización de este tipo de actividades ilícitas se explican por la corrupción generalizada a escala local, provincial y regional. ${ }^{35}$ Los garbanzos eran productos intervenidos por el régimen desde antes de germinar las semillas: las Juntas Agrícolas Locales (primero dependientes de los ayuntamientos y después de las Hermandades de Labradores). Después, los agricultores debían reservar una parte para su consumo o para futuras siembras, entregando el resto al Servicio Nacional de Trigo, encargado de controlar los productos agrícolas intervenidos. Solía contar con un almacén en el pueblo o en la comarca. Para el transporte de las mercancías, era obligatoria una "guía de circulación" visada por la Comisaría General de Abastecimientos y Transportes, otra institución autárquica creada por la dictadura para asegurar la intervención. Los camiones podían ser parados en cualquier momento y, si sus conductores no llevaban esa "guía" sellada convenientemente asegurando su punto de origen y de destino (además de un producto y una cantidad que concordase con el que realmente transportaban), podrían ser detenidos conforme a las leyes de tasas y de abastecimiento. ${ }^{36}$ Así pues, para que la mercancía llegase a su destino

\footnotetext{
${ }^{33}$ Archivo Histórico Provincial de Málaga (AHPM), Gobierno Civil. Fiscalía Provincial de Tasas. Caja 12578, 25-3-1942. También señalaba que a comienzos de marzo "salió del Cortijo del Puntal, del Sr. Lora Vera" (el mismo propietario del caso citado más arriba) "20 fanegas de garbanzos, conducidos por varios cargueros a Alcalá del Valle" (Cádiz).

${ }^{34}$ En concreto fue vocal del grupo olivar de la Hermandad, vocal de la Sección Económica de la HSLG y jefe del grupo de cereales ya en los años cincuenta. Otro hermano suyo, José Jesús, fue jefe de la Hermandad en 1940, además de jefe de la Sección Económica de la misma y presidente de la "Sociedad Casino de Teba". Archivo de las Cámaras Agrarias de Teba (ACAT), sin signatura, Acta de la sesión del grupo de cereales de Teba, 6-7-1949 y Archivo Municipal de Teba, caja 138, campañas de aceite, 27-1-1948. Agradecemos la cesión de esta documentación a Gloria Román Ruiz.

${ }^{35}$ Como se demostró en el caso del mercado negro de trigo en Alicante. Ver: Roque MORENO FONSERET, La autarquía en Alicante (1939-1952). Alicante, Generalitat Valenciana - Institut de Cultura «Juan Gil-Albert», 1994, pp. 179-184.

${ }^{36}$ Legislación emitida entre 1939 y 1941 fundamentalmente. Ver Miguel Ángel DEL ARCO BLANCO, Las alas del ave fénix. La política agraria del primer franquismo (1936-1959). Granada, Comares, 2005, pp. 269-278.
} 
hacía falta, o buenas dosis de suerte, especialmente si el transporte de mercancías se producía entre diversas provincias, o contar con los contactos necesarios para que la Guardia Civil, la Policía o los agentes de la Fiscalía no hiciesen preguntas o mirasen para otro lado. Lo mismo puede decirse cuando la mercancía llegase a su destino y, debido a las grandes cantidades transportadas, fuese descargada, almacenada y comercializada. Como puede verse, la corrupción danzaba en torno a todas las instituciones del régimen, potenciándose incluso por la aparición de instituciones autárquicas que intervenían (y podrían lucrarse) en el proceso. A partir de aquí comenzaba la comercialización a través de pequeños vendedores o pequeñas transacciones que no formaban parte de las instituciones y que, como sabemos, sí fueron duramente castigados por el régimen. ${ }^{37}$

No queremos detenernos demasiado en el papel jugado por los agricultores (propietarios y arrendatarios de todo tipo) en el estraperlo. Hace tiempo se señaló que el recurso al mercado negro, junto a otros factores como la domesticación de la mano de obra o el hundimiento de los salarios, propiciaron la acumulación de capital que, ya en los años cincuenta, se transferiría al sector industrial; ${ }^{38}$ ya mencionamos anteriormente los beneficios que estas prácticas corruptas tendrían en el patrimonio de algunos miembros del campesinado. ${ }^{39}$

Preferimos insistir, en cambio, sobre la participación en el negocio de estraperlo desde distintas escalas de la Administración, evidenciando así su tolerancia o compromiso con las prácticas corruptas y el enriquecimiento de los leales al "Nuevo Estado". Es algo que fue evidente para diversos testigos extranjeros que visitaron España entonces. El historiador Basil Davidson, tras recorrer el país en 1950 sostenía que "la masiva burocracia (tanto civil como militar) constituye hoy la clase oligárquica y la principal beneficiaria del régimen", siendo "normalmente corrupta, eficiente sólo en

\footnotetext{
${ }^{37}$ Algunos ejemplos para la provincia de Málaga: Cristian Matías CERÓN TORREBLANCA, La paz de Franco, la posguerra en Málaga: desde los oscuros años 40 a los grises años 50. Málaga, Universidad de Málaga, 2007, pp. 286 y ss. Otro ejemplo para la provincia de León, referido al trigo: Centro Documental de la Memoria Histórica (CDMD), Incorporados, caja 1448, leg. 4, 16-9-1940.

38 José Luis LEAL, Joaquín LEGUINA, José Manuel NAREDO y Luis TARRAFETA, La agricultura en el desarrollo capitalista español (1940-1970). Madrid, Siglo XXI, 1977, ver Parte I. También: José Manuel NAREDO, La evolución de la agricultura en España (1940-2000). Granada, Universidad de Granada, 2004.

${ }^{39}$ Miguel Ángel DEL ARCO BLANCO, 'Hambre de siglos', op. cit., pp. 184-186.
} 
su propio interés y prueba de todas las ideas que no llevan a una auténtica expansión de la economía". ${ }^{40}$ Todavía algo después, el certero periodista estadounidense Herbert L. Matthews escribiría: "la corrupción es habitual en el Gobierno y en la industria. Algunos altos funcionarios se han enriquecido de forma vergonzosa. Todo es personal. Uno debe saber cómo tratar con la persona adecuada. Con demasiada frecuencia, la ley se aplica sobre el que no tiene influencias, el débil y el pobre, y nunca al rico". ${ }^{41} \mathrm{La}$ línea entre enriquecimiento ilícito y vinculación al régimen, por un lado, y castigo y grupos desfavorecidos, por otra, era clara.

Comenzando por la esfera municipal de la Administración, debemos señalar que los alcaldes fueron un elemento fundamental en el desarrollo del gran estraperlo. Tenían el control de lo que sucedía en la localidad, gestionaban el racionamiento y comandaban las fuerzas de orden público municipales. Los casos son muy numerosos. Ya en 1940, en Carmona (Sevilla) el alcalde y su hermano estaban implicados en un buen organizado negocio de "contrabando" al vender "grandes existencias de trigo" en el municipio, estimándose que "2.000 fanegas de trigo" estaban "repartidas en pequeñas cantidades en graneros de otros tantos vecinos". 42 En ese mismo año, el gobernador de León describía una situación de corrupción generalizada en los municipios de la provincia: "son muchos los alcaldes negligentes que permiten" que "en sus Municipios se especule con los productos de la tierra, y consienten ocultaciones de los mismos, cuando no encubren a sus desaprensivos mercaderes"; pero además, eran los alcaldes "los primeros en vulnerar las órdenes", "son ellos los que venden a un precio superior a la tasa o permiten que lo hagan sus parientes o amigos". ${ }^{43}$ Los gestores de los ayuntamientos, por supuesto, tampoco les fueron a la zaga: en La Rioja fueron numerosos los ediles mezclados en asuntos más o menos turbios para lo que, como reconocía un testimonio, "no daba igual ser un ciudadano más o una

\footnotetext{
${ }^{40}$ Basil DAVIDSON, Report on Spain. Londres, London Caledonian Press, 1951, p. 10.

${ }^{41}$ Herbert L. MATTHEWS, The Yoke and the Arrows. A report on Spain. Londres, Heinemann, 1958, p. 92.

${ }^{42}$ Archivo General de la Administración (AGA), Agricultura. Caja 61/291,

${ }^{43} \mathrm{CDMH}$, Incorporados, caja 1448, leg. 4, 16-9-1940.
} 
persona con posibles". 44 La corrupción municipal respecto a las grandes transacciones en el mercado negro no se limitaba, por tanto, al enriquecimiento de las personas cercanas al régimen: como pudo suceder en la región valenciana, los alcaldes ayudaban a los grandes estraperlistas cuando eran sorprendidos, escribiendo a las autoridades, redactando informes falsos, recurriendo para disminuir las multas o ayudar a los más influyentes. ${ }^{45}$

Otro puntal clave en la corrupción de los cuarenta fueron los gobernadores civiles. Su inmenso poder en la provincia, así como ser los máximos responsables del abastecimiento les otorgaba un papel clave en el desarrollo o persecución del estraperlo. Cuando su implicación en la corrupción era demasiado flagrante, llegaron a producirse ceses. Pudo ser el caso del oficial de ingenieros Paulino Coll Messeguer, gobernador civil de Gerona entre 1939 y 1942. Su papel en oscuros negocios de estraperlo pareció motivar su cese. Tal y como reconocía el cónsul británico de Barcelona: "se rumorea que su salario como gobernador era difícilmente suficiente para permitirse la construcción de una imponente residencia privada y algunas propiedades que ha adquirido". ${ }^{46}$ Por supuesto, el régimen nunca publicitó que fuese cesado por este motivo.

Los mandos inferiores de los gobiernos civiles no escaparon a esta tendencia. En Palencia, en 1944, se destapó un caso de corrupción relacionado con el comercio de la piel y la lana, en el que estaban implicados algunos antiguos mandos sindicales. El gobernador civil abrió una investigación pero, como él mismo afirmaba, los implicados estaban moviendo todos los hilos posibles para que la resolución fuese "favorable", persiguiendo incluso la destitución del gobernador "y las de otras jerarquías de esta jefatura". ${ }^{47}$ La situación en otras provincias no era distinta, y la corrupción se extendía de forma imparable por todas las escalas de la Administración.

\footnotetext{
${ }^{44}$ María Cristina RIVERO NOVAL, Política y sociedad en La Rioja durante el primer franquismo (19361945). Logroño, Instituto de Estudios Riojanos, 2001, p. 340.

${ }^{45}$ Ricard Camil TORRES FABRA, Autarquia i estraperlo. L'economia en un espai rural del País Valencia durant el franquisme. Valencia, Universidad de Valencia, 2005, p. 35.

${ }^{46}$ The National Archives (TNA), Public Record Office (PRO), Foreign Office (FO), 371/31236, Barcelona, 3-7-1942, pp. 7-9.

${ }^{47}$ Domingo GARCÍA RAMOS, Instituciones y vida política durante la guerra civil y el franquismo en Palencia (1936-1975). Tesis Doctoral, UNED, 2003, p. 209.
} 
En Huesca, la situación llegó a tal punto que incluso el automóvil del gobernador civil fue utilizado por su chófer para comercial ilegalmente aprovechando, claro está, que ningún control registraba el vehículo de la mayor autoridad de la provincia". ${ }^{48}$

Y por supuesto, el personal de las instituciones autárquicas hizo su agosto con la aplicación de la política intervencionista. Los casos son numerosos. Las oficinas de la Comisaría de Abastecimientos y Transportes de Cádiz debieron ser un nido de corrupción: en esta región, clave para el contrabando y con puntos tan importantes como el campo de Gibraltar, el gran estraperlo llegó a niveles excepcionales. La implicación del personal de la Comisaría parece clara. En 1947 se prohibió la entrada de personal ajeno a la sección de carburantes por los robos que se estaban produciendo. ${ }^{49}$ Curiosamente, algunos dejaban "sobre su mesa los documentos que tramitaban en el momento de darse la hora del final del trabajo", propiciando el "extravío o desaparición de algunos escritos" (expedientes de sanciones, guías de circulación, etc.). ${ }^{50}$ Otros empleados aprovechaban su privilegiada posición para pedir a sus compañeros de Algeciras "artículos de procedencia extranjera". ${ }^{51} \mathrm{Y}$ por supuesto, la Delegación de Cádiz no estuvo exenta de ceses sonados por corrupción, como el del Subinspector Manuel Rodríguez Rodríguez, ante las "diligencias instruidas" por el gobernador civil. ${ }^{52}$

Otras instituciones autárquicas también participaron en este festival de corrupción a costa siempre del encarecimiento de los precios. Pudo ser el caso del Servicio Nacional del Trigo: un empleado de éste y el delegado sindical del pueblo de Campanillas (Málaga) fueron detenidos en 1946, un año de pésima cosecha, por estraperlo de 1.300 kilos de trigo. ${ }^{53}$ La Fiscalía de Tasas, paradójicamente responsable

\footnotetext{
${ }^{48}$ Carlos DOMPER LASÚS, Por Huesca hacia el imperio. Cultura y poder en el franquismo oscense (1938-1965). Huesca, Instituto de Estudios Altoaragoneses, 2010, p. 51.

${ }^{49}$ Archivo Histórico Provincial de Cádiz (AHPC), Abastecimiento. Caja 11063, Inspector Jefe, 10-111947.

${ }^{50}$ AHPC, Abastecimiento. Caja 11063, Secretario accidental de la Comisaría de Abastecimientos, 22-11948.

${ }^{51}$ AHPC, Abastecimiento. Caja 11063, Secretario de la Comisaría de Abastecimientos, 10-6-1949.

${ }^{52}$ AHPC, Abastecimiento. Caja 11063, Secretario de la Comisaría de Abastecimientos, 26-4-1949.

${ }^{53}$ AHPM, Gobierno Civil. Fiscalía Provincial de Tasas. Caja 12617, Detención de empleado SNT y Delegado Sindical de Campanillas, 1946.
} 
de hacer cumplir los precios oficiales fijados por el gobierno, tampoco escapó a estas corruptelas. En 1948, un informe de la Dirección General de Seguridad sobre Las Palmas advertía sobre la corrupción que carcomía a la Fiscalía Provincial de la isla: tras una inspección, "siendo trasladados varios funcionarios por tener concomitancia con elementos que se dedicaban al estraperlo y recibir dinero, y que los que quedan no son más morales que los que se han ido". ${ }^{54}$ También en Canarias, un informe de la Dirección General de Seguridad de 1946 reconocía que la Fiscalía "no actúa" contra las personas implicadas en el gran estraperlo, sino "contra personas humildes que venden un poco de azúcar, café, harina" ${ }^{55}$ Sin duda la Fiscalía se convirtió en una de las instituciones más odiadas por los más humildes en aquellos años, no sólo por desarrollar la tarea para la que fue creada, sino más bien por cometer los atropellos más brutales y sacar partido del sufrimiento de los más humildes. La actitud corrupta de los agentes debió ser tal que, en no pocas ocasiones, algunas se hicieron pasar por ellos para requisar mercancías o cobrar multas por delitos de estraperlo. ${ }^{56}$

El Ejército, uno de los grandes sostenedores de la dictadura franquista, jugó un papel destacado en los grandes negocios del estraperlo. ${ }^{57}$ Oficiales y suboficiales utilizaban el escudo del triunfante Ejército para llevar a cabo transacciones ilegales de forma impune. Generales como Luis Orgaz eran considerados como corruptos por la diplomacia británica, e incluso Franco tenía noticia de su implicación en un asunto de estraperlo muy importante a través de un informe que se le hizo llegar. ${ }^{58}$ En 1947, un informe sobre Gran Canaria daba cuenta que "algunos oficiales y suboficiales venden de estraperlo artículos alimenticios" enriqueciéndose tanto que se estaban

\footnotetext{
${ }^{54}$ Citado en: Ricardo A. GUERRA PALMERO, Sobrevivir en Canarias. Santa Cruz de Tenerife, Idea, 2006, p. 219.

${ }^{55}$ Archivo Histórico de la Transición en Canarias (AHTDC), Fondo Francisco Fajardo (Universidad de La Laguna). DGS. Caja 2. Legajo 3. Nota informativa de 16 de agosto de 1949. Citado en: Aarón LEÓN ÁLVAREZ, "Falange y la construcción del consenso en Canarias durante el primer franquismo", en Miguel Ángel RUIZ CARNICER, Falange, las culturas políticas del fascismo en la España de Franco (1936-1975). Zaragoza, Instituto Fernando el Católico, 2013, p. 298.

${ }^{56}$ Pedro MONTOLIÚ CAMPS, Madrid en la posguerra. 1939-1946. Los años de la represión. Madrid, Sílex, 2005, p. 180.

${ }^{57}$ En cambio, para Ricardo DE LA CIERVA "no hubo corrupción en las fuerzas armadas". Ver: Historias de la corrupción, op. cit., p. 268.

${ }^{58}$ Ángel VIÑAS, Sobornos, op. cit., p. 418. El informe, Documento 118 en Documentos inéditos para la historia del Generalísimo Franco. Vol. IV. Madrid, Fundación Nacional Francisco Franco, 1992.
} 
generalizando las críticas de la población ante "los pingües negocios que vienen realizando" ${ }^{59}$ Lo mismo sucedía en Madrid: algunos militares aprovechaban sus viajes a Andalucía para recoger aceite para la Comisaría de Abastecimientos y Transportes para comprar por su cuenta y, después, venderlo en Madrid. ${ }^{60}$ Por su parte, un informe diplomático británico informaba minuciosamente sobre el mercado negro en 1946, advirtiendo que los "economatos" del Ejército habían sido "una de las fuentes principales de abastecimiento del mercado negro". ${ }^{61}$ Los vehículos militares también gozaron de patente de corso durante aquellos años, puesto que fueron pocos los casos en los que las fuerzas del orden los detenían para inspeccionarlos. Esto sucedió en Almargen (Málaga), donde el alcalde localizó cinco vagones cargados de garbanzos a un capitán del Ejército sin guía de circulación: no obstante, no pudo detenerlo dado que el oficial aseguraba que estaba autorizado por la Capitanía General, comprometiéndose a "asumir toda la responsabilidad". 62

\section{La reacción del régimen ante el gran estraperlo}

Para cerrar el círculo de la corrupción vinculada al gran estraperlo, debemos también reflexionar sobre la reacción que tuvo el Estado frente a estos suculentos negocios. Rápidamente las altas jerarquías del régimen comprendieron la dificultad de atajar una actividad tan lucrativa. Luis Carrero Blanco, Subsecretario de la Presidencia del Gobierno, admitía al comienzo de la década de los cuarenta que "el estraperlista trabaja con mucha mayor impunidad" que el delincuente común, puesto que las posibilidades de ser castigado por la Justicia eran "mínimas en relación con el número que diariamente se cometen". ${ }^{63}$ Como evidenciamos más arriba, el "Nuevo Estado" tenía conocimiento de la total implicación y complicidad de todas las escalas e

\footnotetext{
${ }^{59}$ Ricardo A. GUERRA PALMERO, Sobrevivir en Canarias. Santa Cruz de Tenerife, Idea, 2006, p. 238

${ }^{60}$ Carlos BARCIELA, Recuerdos del Madrid de la posguerra, Alicante, Universidad de Alicante, 2013, p. 179.

61 TNA, PRO, FO 371/60412, November Report, 1946, 12-12-1946. También mencionado en: Carlos BARCIELA, Recuerdos... op. cit., p. 177.

${ }^{62}$ AHPM, Gobierno Civil. Fiscalía Provincial de Tasas. Caja 12576, alcalde de Almargen a Gobernador, 23-9-1941.

63 Laura DE ANDRÉS CREUS, El preu de la fam: L'estraperlo a la Catalunya de la postguerra. Barcelona, Ara Llibres, 2010, p. 89.
} 
instituciones de la Administración en el gran negocio estraperlista. No obstante, recurrirá a dos vías para hacerle frente. En primer lugar, el endurecimiento de las penas por delitos de estraperlo. Desde la promulgación de las primeras medidas de castigo en 1939 se procederá al obsesivo endurecimiento de las multas y penas para terminar con esa "criminal y antipatriótica conducta", llegando en 1941 a amenazar con "la última pena". ${ }^{64}$ Estas medidas, mengua decirlo, no sólo no acabarán con la corrupción del mercado negro, sino que provocarán que en muchos casos los precios de los productos aumenten exponencialmente, dado que los estraperlistas transferirán a los consumidores el pago de las multas ascendentes impuestas por el gobierno. ${ }^{65}$

En segundo lugar, el régimen desencadenará una propaganda masiva en la prensa, desvinculándose completamente de la corrupción generalizada de la que era protagonista y ofreciendo una imagen de férrea lucha contra el estraperlo. Periódicamente anunciará "campañas para el abaratamiento" del coste de la vida que casi nunca tendrán resultado. Pero sobre todo, se publicarán a bombo y platillo las incautaciones o multas impuestas a los estraperlistas. Era habitual encontrar estas noticias en las portadas o en las primeras páginas de los rotativos, con titulares realmente espectaculares que perseguían convencer a la sociedad de la voluntad de la dictadura para acabar con el fenómeno, así como desvincularse completamente de él. En abril de 1946 La Vanguardia Española publicaba este titular: "La represión contra el estraperlo. Se han incoado 669.000 expedientes y asciende a 761 millones de pesetas el Importe de las sanciones impuestas y géneros incautados". En la noticia se insistía en el cierre de establecimientos, la incautación de toneladas de trigo y en la inminente caída de algunos grandes estraperlistas. Sin embargo, toda noticia era una ilusión, porque la carestía de vida, la escasez y el negocio del mercado negro seguía año tras año. 66

\footnotetext{
${ }^{64}$ La cita, Ley de 24 de junio de 1941 (BOE 5/1/1941). La disposición de la última pena: Ley de 16 de octubre de 1941 (BOE 1941/10/16). Salvo en un oscuro caso, la pena de muerte no llegó nunca a aplicarse ni las sanciones fueron tan graves como las disposiciones legales señalaban. Dionisio RIDRUEJO, Escrito en España. Losada, Buenos Aires, 1962, pp. 104 y 55; y Juan CLAVERA, "EI estraperlo en los años cuarenta", Información Comercial Española, 514 (1976), p. 98.

${ }^{65}$ Así lo reconocían los insistentes informes de la diplomacia británica sobre la situación económica de España. TNA, PRO, FO 371/60411, Report June (8-7-1946) y Report July (8-8-1946)

${ }^{66}$ La Vanguardia Española, 14-4-1946, p. 4. Otro ejemplo para Murcia: "Fiscalía de Tasas. Sanciones", La Verdad, 30-12-1941.
} 
La actitud de Francisco Franco siguió una línea muy similar. Durante la posguerra tendió a presentarse como un adalid de la lucha contra la corrupción y los delitos de estraperlo. Solía proclamar batallas "contra la codicia", e incluso en su discursos de Año Nuevo aseguraba que el Gobierno se encargaría "en un íntimo contacto con los organismos e instituciones" a resolver los problemas de la nación. ${ }^{67}$ Pero en realidad, cuando llegaron a su conocimiento acusaciones sobre enriquecimiento ilícito de sus colaboradores más cercanos miró para otro lado: por ejemplo, cuando tras la guerra se le hizo llegar el rumor que el general Saliquet, uno de los más destacados golpistas de 1936, utilizaba grasas de estraperlo en su fábrica de jabón, el "Caudillo" respondió "A mí dejarme en paz". ${ }^{68}$ Cuando el leal oficial Lorenzo Martínez Fuset le informó de cómo muchas figuras prominentes del régimen "explotan sus cargos, dedicándose a negocios, algunos hasta contrabando", Franco "demostró no tener interés en escuchar y cambió la conversación". ${ }^{9}$ Sin embargo, todo parece indicar que, ante buena parte de los españoles, Franco apareció como alguien que no era responsable de la enorme corrupción de su propio régimen, por supuestamente no conocer lo que realmente estaba sucediendo; algo del todo falso pues, como también demuestra la correspondencia que los españoles corrientes le dirigían durante todos aquellos años informándole de la implicación de las autoridades en los delitos de estraperlo, siempre estuvo bastante bien informado. ${ }^{70}$

En su propaganda, la dictadura ofrecerá una imagen del gran estraperlista como un ser desalmado, anti-español, que nada tiene que ver con el Estado, identificado con el mundo urbano, con el vicio y la desaprensión: se trata de "cuatro desaprensivos, traficantes sucios, pescadores a rio revuelto, parásitos (...). Nada les preocupa, nada les interesa que no sea el vil negocio del oro. Son alimañas que se deslizan en la

\footnotetext{
${ }^{67}$ Ambas citas en "Una nueva batalla" y "La verdad española", en Francisco FRANCO, Textos de doctrina política. Palabras y escritos de 1945 a 1950. Madrid, Publicaciones Españolas, 1951, pp. 647 y 114, respectivamente.

${ }^{68}$ Rafael ABELLÁ, Por el Imperio hacia Dios: crónica de una posguerra, Barcelona, Planeta, 1978; más ejemplos y citado en Antonio CAZORLA, Las políticas de la victoria: la consolidación del Nuevo Estado franquista (1938-1953). Madrid, Marcial Pons, p. 86.

69 Francisco FRANCO-SALGADO ARAUJO, Mis conversaciones privadas con Franco. Barcelona, Planeta, 1976, p. 37.

${ }^{70}$ Antonio CAZORLA, Cartas a Franco de los españoles de a pie (1936-1945), Madrid, RBA, 2014, sobre el mito de la bondad de Franco, p. 21; cartas sobre el estraperlo: pp. 321-324 y 327.
} 
oscuridad, cazando a sus víctimas que, en esta ocasión, es la raza y la vida de su pueblo". ${ }^{71}$ Esta imagen se reflejará también en la gran pantalla: en la película Surcos, dirigida por el falangista José Antonio Nieves Conde, el gran estraperlista ("El Chamberlain", original apodo que apuntaba a lo británico) será caracterizado como un personaje urbano, antipatriótico, inmoral, que corrompe a la juventud, con sobrepeso y completamente alejado de las instituciones del régimen. ${ }^{72}$

No debemos descartar que, pese a la extensión de la corrupción estatal, la propaganda del franquismo sobre su persecución de los grandes delitos de estraperlo diese algún resultado. La ausencia total de derechos democráticos y el control total de los medios de comunicación permitieron al régimen presentarse como un luchador incansable frente al enriquecimiento ilícito. Ejemplo de ello pudo ser el "Caso del Consorcio de la Panadería de Madrid". A finales de 1947, los líderes de esta institución encargada de suministrar el pan y la harina a la capital se vieron envueltos en un caso de estraperlo de grandes dimensiones. Al parecer, habían desviado toneladas de trigo importado desde Argentina, destinándolas al mercado negro. ${ }^{73} \mathrm{El}$ malestar de la población fue tal que incluso se produjeron manifestaciones y protestas, marchando incluso hasta los edificios de algunos ministerios del gobierno. El régimen utilizó este malestar a su favor: en enero de 1948 el Consejo de Ministros impuso una sanción de 28.830.000 pesetas a los mandos dirigentes. La prensa aseguró que de este modo "la justicia de Franco ampara los intereses del pueblo español”. ${ }^{74}$ Además, el 2 de febrero tuvo lugar una masiva manifestación contra los responsables orquestada por la dictadura, que había incluso repartido octavillas el día anterior. ${ }^{75}$ La multitudinaria manifestación de unas 5.000 personas discurrió por las calles de Madrid, agolpándose frente al Ministerio de Trabajo. ${ }^{76}$ Tras recibir a una comisión, ante la continuidad de los vítores, el ministro falangista José Antonio Girón dirigió unas palabras a la multitud desde el balcón del edificio: "En estos momentos difíciles que atravesamos, debemos

\footnotetext{
71 “Comentarios higiénicos al straperlo”, Hechos. Revista mensual ilustrada, Dr. Villarejo, s. f. (¿1941?).

72 Surcos, de José Antonio Nieves Conde (1951). Película.

${ }^{73}$ Rafael ABELLÁ, Crónica de una Posguerra (1939-1955). Barcelona, Ediciones B, 2008, p. 158.

74 El Alcázar, 31 de enero de 1948, p. 1.

${ }^{75}$ ABC, 3 de febrero de 1948, p. 17.

${ }^{76}$ Arriba, 3 de febrero de 1948.
} 
unirnos todos los españoles honrados en torno al Caudillo para dar la batalla a los vividores y especuladores». ${ }^{77}$ En todo el momento el régimen se desvinculó de lo sucedido, culpando a los estraperlistas y obviando que algunos de ellos habían contado con la connivencia de cargos estatales como, por ejemplo, el Comisario de Abastecimientos de la capital. ${ }^{78}$

La evidencia última del calado de la corrupción respecto al gran estraperlo y de la verdadera voluntad del régimen en atajarlo es que, como ya apuntamos, los responsables de las grandes transacciones fueron detenidos en pocas ocasiones, cayendo el peso de la ley especialmente sobre los pequeños estraperlistas. ${ }^{79}$ Pero además, cuando fueron impuestas grandes multas los grandes estraperlistas inventaron vías para hacerles frente o utilizaron sus contactos políticos para no ser castigados. Así actuaron algunos industriales catalanes que, además de gozar en muchos casos de la tolerancia del gobernador civil, idearon un "seguro común" para abonar las multas impuestas por delitos de estraperlo (que a veces iban de 1 a 3 millones de pesetas). ${ }^{80}$ En otros casos, como algún estudio local de la provincia de Cádiz ha revelado, incluso las multas no eran abonadas. ${ }^{81}$ Como sucedía durante todo el desarrollo del gran estraperlo que hemos descrito, los estraperlistas cercanos al régimen (o parte de él) disponían también de contactos y medios para frenar las multas impuestas e incluso las condenas. Un informe conservado entre los papeles personales de Franco, firmado por el Director General de Prisiones (entre otros) y remitido al Ministro de Justicia es claro al respecto. ${ }^{82}$ Relataba infinidad de casos por los que los condenados por delitos de gran estraperlo recurrían a autoridades militares, al poder judicial o incluso a los responsables de las prisiones para no cumplir las

\footnotetext{
77 Íbidem.

${ }^{78}$ Todo el caso, relatado en tono exculpatorio por uno de los considerados culpables: J. de GRATTIS, Rejas sin votos. El libro aúreo del Consorcio de la Panadería de Madrid. Madrid, 1969.

${ }^{79}$ Ejemplos de Almería: Miguel GÓMEZ OLIVER y Miguel Ángel DEL ARCO BLANCO, "El estraperlo: forma de resistencia...", op. cit. y Óscar J. RODRÍGUEZ BARREIRA, Migas con miedo. Prácticas de resistencia en el primer franquismo. Almería 1939-1952. Almería, Universidad de Almería, 2008, pp. $237-$ 239.

${ }^{80}$ TNA, PRO, FO 371/31234, From Madrid, 17-2-1942, pp. 114-116.

${ }^{81}$ Beatriz PÉREZ GONZÁLEZ, Estraperlo en Cádiz. La estrategia social. Cádiz, Quorum Editores, 2004, p. 84.

82 "Detenidos a causa de estraperlo", Documentos inéditos para la historia del Generalísimo Franco. Vol. II-2. Madrid, Fundación Nacional Francisco Franco, 1992, pp. 394-395.
} 
penas. Por ejemplo, se daba noticia de un caso donde 69 individuos habían sido condenados y en lugar de cumplir la pena en prisión disfrutaban de una "prisión atenuada en sus domicilios". Otro de los casos descritos era el de José Banús y Cándido Solá, que fueron condenados por estraperlo a dos años y medio: su pena fue cumplida entre ingresos inexplicablemente tardíos en prisión, estancias cortas en la cárcel, prisiones atenuadas en sus domicilios e incluso abonos de la prisión preventiva. Como sabemos, Banús Masdeu fue uno de los promotores inmobiliarios predilectos del régimen franquista, tanto como para que su empresa fuese comisionada para construir el Valle de los Caídos. ${ }^{83}$

Además del lógico castigo a los responsables del gran estraperlo, el régimen franquista podía haber adoptado una medida esencial para terminar con el problema de la escasez, el hambre y el mercado negro: poner fin a la intervención económica y, en definitiva, a la política autárquica. Hubo momentos justificados para ello, como en el trágico año de 1946. Ese fue uno de los más duros de la posguerra española. Sin embargo, el "Nuevo Estado" renunció a cualquier viraje en su política económica. Como reconocía un telegrama del embajador italiano en Madrid en agosto de ese año, el Consejo de Ministros presidido por Franco se había reunido de urgencia para examinar "en detalle la situación económica de España y en especial la alimenticia que en el momento actual es muy grave" por la tremenda "escasez de géneros alimenticios y su altísimo costo". Sin embargo, Franco se limitó "a escuchar la exposición de los dirigentes de los ministerios técnicos", sin tomar "ninguna decisión sobre el tema". ${ }^{84}$ También hubo presiones desde diversos sectores del régimen: desde algunas revistas técnicas se promovió una relajación del intervencionismo, con el fin de promover precios oficiales más remuneradores y promover el fin del estancamiento económico; ${ }^{85}$ en 1950 se celebró el I Congreso Nacional de Ingeniería Agronómica, donde se

\footnotetext{
${ }^{83}$ Mariano SÁNCHEZ SOLER, Ricos por la guerra de España, op. cit., pp. 216-219.

${ }^{84}$ Archivio Storico Diplomatico-Ministero degli Affari Esteri (AMAE), Affari Politici. Spagna 1946-1950. Busta 1, Telegrama 6-8-1946.

${ }^{85}$ Carlos BARCIELA, "La España del estraperlo", op. cit., p. 120.
} 
produjo un cruento debate entre los partidarios de continuar con la autarquía o propiciar una liberalización económica. ${ }^{86}$

Tendrían que llegar los primeros años cincuenta cuando, ante una economía agotada, el malestar popular manifestado en protestas como la de Barcelona en 1951 o la indudable presión americana, hiciesen al régimen abandonar el intervencionismo autárquico más férreo. ${ }^{87}$ Después de evidenciar la implicación de la Administración de la dictadura franquista en el negocio del gran estraperlo, no es nada descabellado sostener que los cuadros del régimen fueron una fuerza a tener en cuenta para frenar una liberalización económica que terminaría con sus lucrativos negocios.

\section{Conclusiones}

En nuestro trabajo tratamos de abordar uno de los ejemplos más claros de corrupción durante el franquismo: el gran estraperlo. Un fenómeno que tuvo lugar durante los años de posguerra, mientras que la política autárquica estuvo vigente en todo su vigor (1939-1952). Encajó perfectamente en la definición de corrupción política según la cual, a través de la utilización de los mecanismos de poder, se genera un enriquecimiento personal.

El gran estraperlo es una evidencia más de que la corrupción fue consustancial a la dictadura. Durante los años cuarenta fue un elemento estructural, que se desarrolló durante largo tiempo, de forma constante y nunca de forma esporádica. Lo más terrible de ello es que el enriquecimiento se produjo siempre a costa de las clases sociales más bajas o alejadas del poder: los precios desorbitados de productos alimenticios o manufacturados fueron en parte consecuencia de la tremenda escasez. Paradójicamente, las dificultades económicas, el sufrimiento y el hambre, hicieron posible el enriquecimiento de los beneficiados del gran estraperlo.

\footnotetext{
${ }^{86}$ Carlos BARCIELA y María Inmaculada LÓPEZ ORTIZ, "La ingeniería agronómica en la encrucijada. EI congreso nacional de 1950". Historia Agraria, 61 (2013), pp. 158-159.

${ }^{87}$ Carlos BARCIELA y María Inmaculada LÓPEZ ORTIZ, "El fracaso de la política agraria del primer franquismo, 1939-1959. Veinte años perdidos para la agricultura española", Carlos BARCIELA (Ed.), Autarquía y mercado negro. El fracaso económico del primer franquismo, 1939-1959, Barcelona, Crítica, 2003, pp. 75-79.
} 
Buena parte de los protagonistas del gran estraperlo pertenecían a la Administración del régimen franquista. En todas sus escalas se produjo una corrupción generalizada. La fidelidad política al régimen habilitaba para acceder a las instituciones $\mathrm{y}$, desde estas, participar activamente y enriquecerse con una corrupción de unas dimensiones hasta entonces desconocidas. Como mínimo, hemos demostrado que alcaldes y gestores en municipios; gobernadores civiles y sus allegados en el poder provincial; funcionarios de las instituciones autárquicas; y miembros del Ejército, estuvieron implicados en una corrupción generalizada que jugaba con el hambre para propiciar el progreso económico de los apoyos sociales del régimen.

Dicho esto, evidentemente era incongruente que el "Nuevo Estado" pusiese remedio a una corrupción de tal calado de la que, en gran parte, su personal era actor y responsable. No obstante, respondió con impresionantes campañas de propaganda, tratando de desvincularse del fenómeno y generando una imagen del gran estraperlista como alguien desalmado y antipatriota. Franco fue presentado como el buen Caudillo que no sabía lo que estaba sucediendo. Nada más lejos de la realidad. Como también hemos creído evidenciar, cuando los grandes estraperlistas fueron sorprendidos utilizaron sus contactos y su cercanía al régimen para evitar las multas, sanciones y encarcelamientos. La impunidad también estuvo garantizada.

Hace años, refiriéndose al círculo más íntimo de Francisco Franco, Ramón Garriga señaló que éste cultivaba la corrupción y el favoritismo como norma política, partiendo del principio de que quieres colaboraban con el régimen serían fieles mientras todo les fuese bien económicamente. ${ }^{88} \mathrm{~A}$ tenor de lo demostrado en este artículo, pensamos que no es demasiado descabellado extender esta afirmación a una parte de los que sirvieron al "Caudillo" desde las instituciones durante los años cuarenta, contribuyendo a explicar así la estabilidad del régimen en esos años y posteriores. Todo ello nos deja, contradiciendo el testimonio con el que comenzábamos nuestro trabajo, una dictadura donde la corrupción estuvo tan presente como para formar parte de su naturaleza.

\footnotetext{
${ }^{88}$ Ramón GARRIGA, La señora del Pardo. Barcelona, Planeta, 1979, pp. 224-227, 240-244, 248-253.
} 